\title{
Analisis Rantai Markov untuk Mengetahui Peluang Perpindahan Merek Kartu Seluler Pra Bayar GSM (Studi Kasus Mahasiswa Fakultas Pertanian Unsrat Manado)
}

\author{
Denis G. Alloa*, Djoni Hatidjaa, Marline Paendong a \\ aJurusan Matematika, FMIPA, Unsrat, Manado
}

KATA KUNCI

Pengguna GSM

Perpindahan Merek

Rantai Markov

\section{K E Y O R D S}

\section{GSM users}

Brand Switching

Markov Chain
AVAILABLE ONLINE

30 Januari 2013

\section{A B S T R A K}

Penelitian ini bertujuan untuk mengetahui peluang perpindahan konsumen merek kartu seluler GSM ke merek kartu seluler GSM lainnya serta membuat prediksi peluang perpindahan konsumen merek kartu seluler GSM dikalangan mahasiswa pada masa yang akan datang. Data yang digunakan dalam penelitian ini adalah data primer yang dikumpulkan melalui penyebaran kuesioner pada mahasiswa Fakultas Pertanian Universitas Sam Ratulangi Manado. Total sampel dalam penelitian ini adalah 87 orang mahasiswa. Berdasarkan hasil analisis Rantai Markov dengan menggunakan software QM 2.2 for window, diperoleh bahwa pada mahasiswa Fakultas Pertanian UNSRAT pengguna GSM untuk merek AS dan Simpati yang pada awal mendominasi persentase pengguna dan bahkan pada tahun-tahun berikutnya cenderung tetap mendominasi jumlah pengguna GSM. Pada tingkat kedua merek GSM IM3 dan GSM Tri yang mendominasi pengguna GSM, dimana keduanya masing-masing mencapai nilai antara 5-10\% dari total pengguna.Dan selanjutnya, merek GSM XL, hanya mampu mencapai angka di bawah 5\% saja.Sedangkan merek GSM Axis dan Mentari belum mampu untuk masuk pada pasar dalam populasi mahasiswa Fakultas Pertanian UNSRAT Manado.

\section{A B S T R A C T}

This study aims to determine the changes of consumers switching between brands of GSM and make predictions of consumer migration opportunities of each brand GSM among students in the future. The data used in the study is primary data collected through a questionnaire on the students of the Faculty of Agriculture, University of Sam Ratulangi Manado. The number of samples taken was 87 students. Based on markov chain analysis using QM 2.2 sofware for windows, found that the students of the Faculty of Agriculture UNSRAT brand GSM users AS and Simpati as a large percentage of users in early and even in later years tend to continue to dominate the numbers of GSM users. On the second level brand GSM users IM3 and Tri dominating users, where each of them reaches a value between $5-10 \%$ of the total users. The next brand GSM XL, only able to reach below $5 \%$. While the brand GSM Axis and Mentari has not been able to enter the market in the agriculture faculty of the college population University of Sam Ratulangi Manado. 


\section{Pendahuluan}

Perkembangan teknologi telekomunikasi yang sangat pesat memberikan pengaruh yang sangat besar bagi perusahaan jasa telekomunikasi di Indonesia.Salah satu perkembangan teknologi telekomunikasi adalah perkembangan telekomunikasi seluler. Mobilitas serta meningkatnya kebutuhan masyarakat dalam komunikasi dimana saja dan kapan saja menjadikan faktor pendorong munculnya teknologi berbasis seluler (Mahe, 2007).

Global System for Mobile communications (GSM) merupakan alat telekomunikasi yang siap dipakai sewaktu-waktu dimana saja dan kapan saja.Persaingan ketat antar perusahaan kartu seluler telah menjadikan perusahaan kartu seluler berlombalomba memberikan tawaran yang menarik kepada pelanggan maupun calon pelanggannya, dengan tujuan untuk menarik pelanggan sebanyakbanyaknya.Berdasarkan pengamatan di pasaran, bahwa semakin banyaknya pilihan merek GSM yang ditawarkan, maka konsumen akan selektif dan memilih merek GSM yang dirasakan sesuai dengan keinginan dan kebutuhannya.. Hal ini menuntut perusahaan GSM lebih kreatif dan menarik perhatian konsumen sehingga konsumen tetap menggunakan produk tersebut dan tidak beralih pada merek lain.

Adapun perhitungan peluang perpindahan merek dihitung menggunakan metode rantai markov yang diperkenalkan oleh matematikawan asal Rusia A.A. Markov (1856-1922).Metode rantai Markov juga dapat memperkirakan peluang konsumsi masingmasing merek GSM saat ini maupun di masa mendatang.Oleh karena itu penelitian yang akan dilakukan ini difokuskan pada perpindahan penggunaan merek kartu seluler pra bayar GSM oleh para mahasiswa Fakultas Pertanian UNSRAT Manado khususnya yang menggunakan kartu seluler pra bayar GSM saja sebagai alat komunikasi pribadi mereka.

Dengan tujuan ntuk mengetahui peluang serta memprediksi perpindahan merek kartu peluang perpindahan konsumen merek kartu seluler GSM di kalangan mahasiswa pada masa yang akan datang.

\subsection{Rantai Markov (Markov Chains)}

Analisis Rantai Markov adalah suatu metode yang mempelajari sifat-sifat suatu variabel pada masa sekarang yang didasarkan pada sifat-sifat masa lalu dalam usaha menaksir sifat-sifat variabel tersebut di masa yang akan datang. Dalam analisis markov yang dihasilkan adalah suatu informasi probabilistik yang dapat digunakan untuk membantu pembuatan keputusan, jadi analisis ini bukan suatu teknik optimasi melainkan suatu teknik deskriptif. Analisis Markov merupakan suatu bentuk khusus dari model probabilistik yang lebih umum dikenal dengan proses Stokastik (Stochastic process)(Sitindaon, 2010).

Jika pada waktu $t$ proses stokastik $\left\{X_{t}, t=\right.$ $0,1, \ldots\}$ berada pada state $i$, maka kita tuliskan kejadian ini sebagai $X_{t}=i$. Proses stokastik yang mempunyai sifat khusus yaitu untuk semua $i_{0}, \ldots, i_{t-1}, i, j$ dan semua $t \geq 0$, berlaku

$$
\begin{gathered}
P\left\{X_{t+1}=j \mid X_{0}=i_{0}, \ldots, X_{t-1}=i_{t-1}, X_{t}=i\right\} \\
=P\left\{X_{t+1}=j \mid X_{t}=i\right\}
\end{gathered}
$$

\subsection{Matriks Peluang Transisi}

Jika sebuah rantai Markov $\left\{X_{t}, t=0,1,2, \ldots\right\}$ dengan ruang state $\{0,1, \ldots \mathrm{M}\}$, maka peluang sistem itu dalam state $i$ pada suatu state $j$ pada pengamatan sebelumnya dilambangkan dengan $P_{i j}$ dan disebut peluang transisi dari state $i$ ke state $j$. Matriks $\mathbf{P}=\left[\mathrm{p}_{\mathrm{ij}}\right]$ disebut matriks transisi rantai Markov (Howard and Rorres, 2004). Jadi,

$$
\begin{array}{ccccc}
\text { state } & 0 & 1 & \cdots & \mathbf{M} \\
& \left.\mathbf{P}=\begin{array}{cccc}
P_{00} & P_{01} & \cdots & P_{0 M} \\
& 0 \\
& 1 \\
P_{10} & P_{11} & \cdots & P_{1 M} \\
\vdots & \vdots & \vdots & \vdots \\
P_{M 0} & P_{M 1} & \cdots & P_{M M}
\end{array}\right]
\end{array}
$$

Dimana elemen-elemen dari matriks $\mathbf{P}$ bernilai tak negatif dan jumlah elemen-elemen pada satu baris di matriks peluang transisi ini harus sama dengan 1.

\subsection{Peluang Transisi n-step}

Hiller dan Liberman (2008) mendefinisikan bahwa peluang transisi $n$-step $P_{i j}^{(n)}$, adalah peluang bersyarat suatu sistem yang berada pada state $I$ akan berada pada state $j$ setelah proses mengalami $n$ transisi. Jadi,

$$
P_{i j}^{(n)}=P\left\{X_{t+n}=j \mid X_{t}=i\right\}
$$

Oleh karena $P_{i j}^{(n)}$ adalah peluang bersyarat, peluang tersebut harus bernilai tak negatif, dan oleh karena prosesnya harus membuat perubahan ke state yang lain maka peluang tersebut harus memenuhi sifat berikut ini.

1. $P_{i j}^{(n)} 0$, untuk semua $i$ dan $j ; n=1,2, \ldots$,

2. $\sum_{j=0}^{M} P_{i j}^{(n)}=1$ untuk semua $i ; n=1,2, \ldots$.

Matriks peluang transisi $n$ - step,

$$
\begin{aligned}
& \begin{array}{lllll}
\text { State } & 0 & 1 & \ldots & \mathrm{M}
\end{array}
\end{aligned}
$$

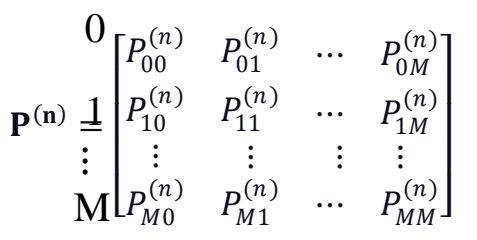

Ketika $n=1$, maka $P_{i j}^{(1)}=P_{i j}$ 


\subsection{Persamaan Chapman-Kolmogorov}

Persamaan Chapman-Kolmogorov merupakan suatu metode untuk menghitung peluang transisi $n$ step.

$$
P_{i j}^{(n)}=\sum_{k=0}^{M} P_{i k}^{(m)} P_{k j}^{(n-m)}
$$

Persamaan di atas menunjukkan bahwa perubahan dari state ke $i$ ke state $j$ sebanyak $n$-step, proses ini akan berada dalam beberapa state $k$ setelah tepat $m$ (kurang dari $n$ ) state. Oleh karena itu, $P_{i k}^{(m)} P_{k j}^{(n-m)}$ adalah peluang bersyarat dengan titik mulai state $i$, proses menuju ke state $k$ setelah $m$ step dan kemudian ke state $j$ setelah $n-m$ step. Dengan demikian, penjumlahan peluang bersyarat terhadap semua $k$ yang mungkin akan menghasilkan $P_{i j}^{(n)}$ (Hiller dan Liberman, 2008).

\subsection{Vektor Keadaan (State Vector)}

State atau keadaan pada rantai Markov yang ditulis dalam bentuk vektor yang dinamakan vektor state (state vector). Vektor state untuk sebuah pengamatan pada suatu rantai Markov dengan $X(t)$ state adalah vektor baris $x$. Dapat dituliskan

$$
x=\left[x_{1}, x_{2}, \ldots, x_{i}\right]
$$

Jika $\mathbf{P}$ merupakan matriks transisi rantai Markov dan $x^{(n)}$ adalah vektor state pada pengamatan ke-n, maka

$$
x^{(n)}=\mathrm{P}^{n} x^{0}
$$

Mulyono (2007) mengemukakan bahwa proses markov akan menuju kondisi steady state (keseimbangan) artinya setelah proses berjalan beberapa periode, peluang status akan selalu tetap.

\subsection{Merek dan Peran Merek}

Merek adalah nama, istilah, tanda, simbol, desain atau kombinasi diantaranya, yang bertujuan untuk mengidentifikasi barang atau jasa dari penjual atau sekelompok penjual dan mendefinisikan mereka dari pesaingnya (Kotler, 2007). Menurut Kotler (2007) peran merek secara lebih spesifik dalam aktivitas pemasaran adalah sebagai berikut :

1. Merek mampu membantu konsumen untuk mengidentifikasi produk yang mungkin memberikan benefit pada mereka.

2. Merek memberikan informasi pada konsumen tentang kualitas produk.

3. Konsumen yang selalu memberikan pembelian produk dengan merek yang sama akan mendapat fitur, benefit dan kualitas yang sama setiap kali mereka membelikan produk tersebut.

4. Merek bisa memberikan proteksi pada keunikan suatu fitur yang mungkin akan ditiru oleh perusahaan lain.

5. Merek akan membatu penjualan untuk melakukan segmentasi pasar.

\subsection{Perpindahan Merek (Brand Switching)}

Brand switching adalah kegiatan seorang pengguna melakukan perpindahan merek dari produk yang satu ke produk lainnya karena alasan tertentu. Brand switching ini merupakan bagian dari loyalitas merek dimana seorang pengguna yang setia menggunakan merek tertentu

\section{Metode}

\subsection{Data}

Penelitian ini berlangsung pada tanggal 13 sampai 30 Agustus 2012, bertempat di Fakultas Pertanian UNSRAT Manado, menggunakan metode survei.Data primer dikumpulkan dengan melakukan penyebaran kuesioner kepada mahasiswa.Populasi dari penelitian ini adalah mahasiswa Fakultas Pertanian yang aktif hingga tahun ajaran 2012/2013 yang memiliki handphoneGSM. Berdasarkan survei bahwa jumlah mahasiswa Fakultas Pertanian yang memiliki handphone GSM sebanyak 660 orang mahasiswa yang diasumsikan bahwa jumlah populasi dari 660 mahasiswa menggunakan merek kartu pra bayar GSM.

\subsection{Analisis Data}

Tahapan analisis yang dilakukan dalam rantai Markov (Djan dan Ruvendi, 2006) adalah sebagai berikut :

a. Membuat tabel jumlah pengguna kartu seluler dari masing-masing merek baik saat sekarang maupun sebelumnya.

b. Membuat tabel perpindahan merek (Brand Switching pattern), yaitu data perubahan atau pergeseran dari suatu merek ke merek lainnya.

c. Membuat matriks peluang transisi $(P)$.

Membuat prediksi jumlah konsumen untuk tahun 2013-2015 menggunakan rumus $x^{(n)}=x^{0} \boldsymbol{P}^{n}$ yaitu mengalikan matriks kejadian dengan matriks peluang transisinya (P). Dimana matriks $\mathrm{P}$ bersifat konstan.

\section{Hasil dan Pembahasan}

Merek kartu seluler pra bayar GSM yang digunakan dapat dilihat pada Tabel 1 sementara Perpindahan merek dapat dilihat Tabel 2.

Tabel 1 - Merek Kartu Seluler Pra Bayar GSM yang Digunakan

\begin{tabular}{|l|l|l|l|}
\hline No. & $\begin{array}{l}\text { Merek } \\
\text { GSM }\end{array}$ & $\begin{array}{l}\text { Jumlah } \\
\text { Responden } \\
\text { (Orang) }\end{array}$ & $\begin{array}{l}\text { Persentase } \\
(\%)\end{array}$ \\
\hline 1. & AS & 49 & 56,32 \\
\hline 2. & Axis & 0 & 0 \\
\hline 3. & IM3 & 7 & 8,05 \\
\hline 4. & Mentari & 0 & 0 \\
\hline 5. & Simpati & 20 & 22,98 \\
\hline 6. & Tri & 8 & 9,20 \\
\hline 7. & XL & 3 & 3,45 \\
\hline Jumlah & 87 & 100 \\
\hline
\end{tabular}


Tabel 2 - Perpindahan Merek (Brand Switching)

\begin{tabular}{|c|c|c|c|c|c|c|c|c|c|}
\hline & \multirow[b]{2}{*}{ Merek GSM } & \multicolumn{8}{|c|}{ Ke Merek } \\
\hline & & 里 & $\frac{n}{x}$ & $\sum^{M}$ & 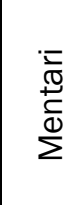 & 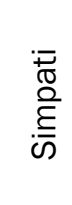 & $\check{E}$ & $\vec{x}$ & 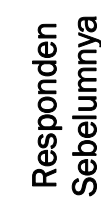 \\
\hline \multirow{8}{*}{ 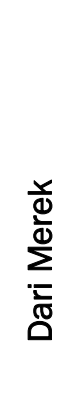 } & AS & 28 & 0 & 5 & 0 & 1 & 4 & 1 & 39 \\
\hline & Axis & 0 & 0 & 0 & 0 & 0 & 0 & 0 & 0 \\
\hline & IM3 & 3 & 0 & 2 & 0 & 2 & 1 & 0 & 8 \\
\hline & Mentari & 0 & 0 & 0 & 0 & 0 & 0 & 0 & 0 \\
\hline & Simpati & 2 & 0 & 0 & 0 & 15 & 0 & 0 & 17 \\
\hline & Tri & 14 & 0 & 0 & 0 & 2 & 3 & 0 & 19 \\
\hline & $X L$ & 2 & 0 & 0 & 0 & 0 & 0 & 2 & 4 \\
\hline & Responden Saat ini & 49 & 0 & 7 & 0 & 20 & 8 & 3 & 87 \\
\hline
\end{tabular}

Selanjutnya dari tabel di atas tersebut, dibuat Tabel Peluang Transisi (P) yang ditunjukkan pada Tabel 3.

Tabel 3 - Peluang Transisi (P)

\begin{tabular}{|c|c|c|c|c|c|}
\hline \multirow[b]{2}{*}{ Dari Merek } & \multicolumn{5}{|c|}{ Ke Merek } \\
\hline & $\infty$ & $\stackrel{m}{\sim}$ & $\bar{\pi}_{0}^{\pi}$ & $=$ & $\perp$ \\
\hline AS & 0,72 & 0,13 & 0.025 & 0,1 & 0,025 \\
\hline IM3 & 0,38 & 0,25 & 0,25 & 0,12 & 0 \\
\hline Simpati & 0,12 & 0 & 0,88 & 0 & 0 \\
\hline Tri & 0,74 & 0 & 0,1 & 0,16 & 0 \\
\hline$X L$ & 0,5 & 0 & 0 & 0 & 0,5 \\
\hline $\begin{array}{l}\text { Konsumsi Masing-masing } \\
\text { Merek GSM }\end{array}$ & 0,56 & 0,08 & 0,23 & 0,1 & 0,03 \\
\hline
\end{tabular}

Bila diasumsikan bahwa perpindahan merek GSM stabil maka dapat dibuat matriks peluang transisi $\mathbf{P}$,

$$
\boldsymbol{P}=\begin{array}{cccccc}
1 & 2 & 3 & 4 & 5 \\
1 \\
3 \\
4 \\
5
\end{array}\left[\begin{array}{ccccc}
0,72 & 0,13 & 0,025 & 0,1 & 0,025 \\
0,38 & 0,25 & 0,25 & 0,12 & 0 \\
0,12 & 0 & 0,88 & 0 & 0 \\
0,74 & 0 & 0,1 & 0,16 & 0 \\
0,5 & 0 & 0 & 0 & 0,5
\end{array}\right]
$$

Dengan vektor periode awal,

$$
\boldsymbol{x}=\begin{array}{ccccc}
1 & 2 & 3 & 4 & 5 \\
{[0,56} & 0,08 & 0,23 & 0,1 & 0,03]
\end{array}
$$

1= Merek GSM AS,2=Merek GSM IM3,3 = Merek GSM Simpati, 4 = Merek GSM Tri, 5 = Merek GSM XL
Vektor $\mathbf{x}$ merupakan vektor kejadian atau vektor awal diperoleh dari Tabel 5 yang dibuat dalam bentuk peluang. Untuk merek GSM AS, pada $x_{1}=0,56$, nilai tersebut diperoleh dengan membagi jumlah konsumen merek GSM AS dengan jumlah konsumen responden seluruhnya, yaitu $49 / 87=0,56$. Dan demikian seterusnya sampai dengan $x_{5}=0,03$ diperoleh dari jumlah konsumen merek GSM XL dibagi dengan jumlah konsumen responden seluruhnya $3 / 87=0,03$.

Prediksi jumlah konsumen kartu seluler pada periode yang akan datang ditunjukkan pada Gambar 1. 


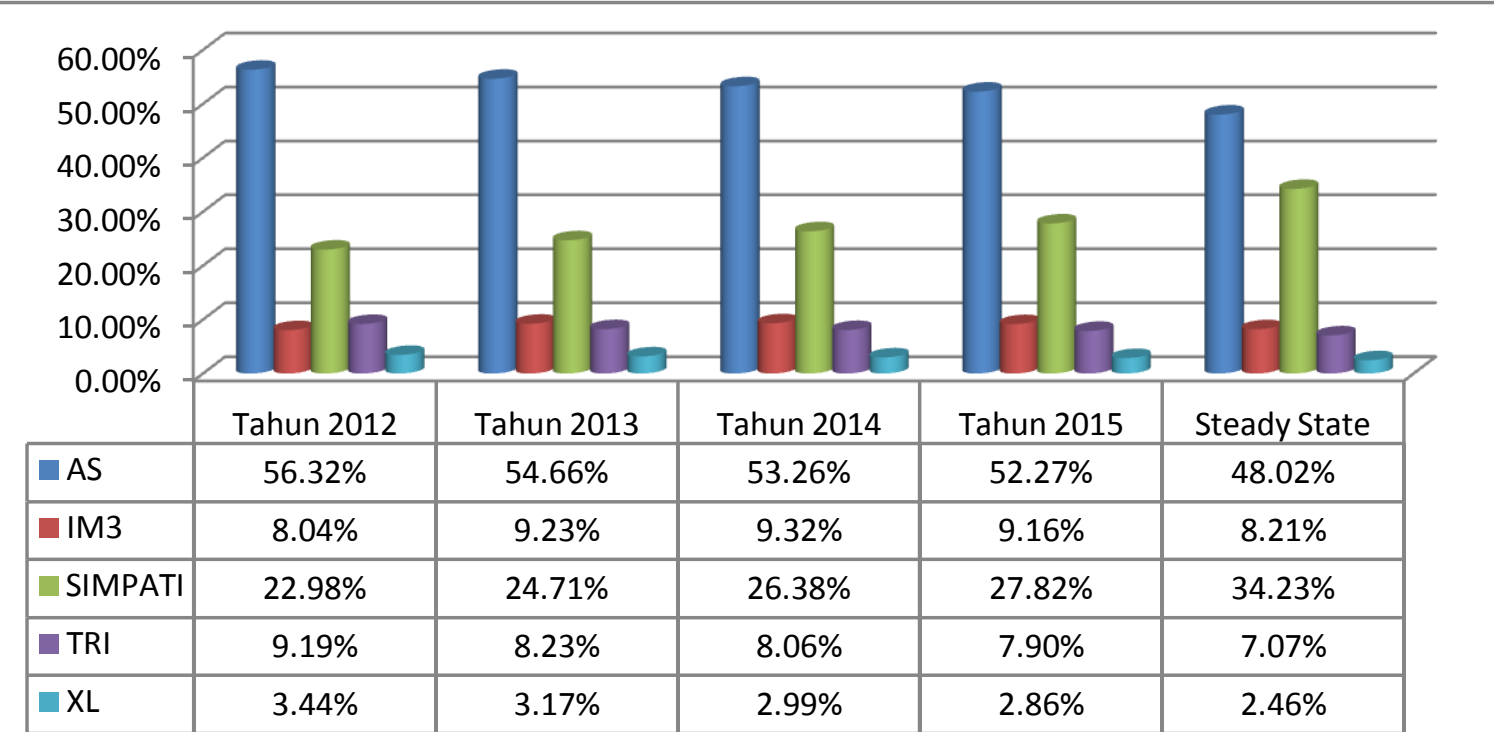

Gambar 1 - Prediksi jumlah konsumen kartu seluler pada periode yang akan datang.

Proses markov akan menuju kondisi steady state (keseimbangan) artinya setelah proses berjalan beberapa periode, maka nilai matriks Peluang akan selalu tetap (Mulyono, 2007). Pada kasus ini berdasarkan hasil pehitungan rantai markov diketahui bahwa nilai peluang konsumen dari masing-masing merek GSM akan konvergen ke satu nilai, atau berada pada kondisi steady state pada transisi ke 49, ini dilihat berdasarkan nilai-nilai peluang pada masing-masing merek GSM tetap atau konstan, dan tidak akan berubah pada transisi-transisi berikutnya dengan nilai masing-masing peluang konsumsi merek GSM AS 48,02\%, merek GSM IM3 8,21\%, merek GSM Simpati 34,23\% merek GSM Tri 7,07\%, dan merek GSM XL 2,46\%.

\section{Kesimpulan}

Matriks peluang dan prediksi peluang perpindahan pengguna GSM yaitu pengguna AS awalnya relatif besar sebanyak 56,32\% lalu sedikit turun menjadi 54,66\% (pada 2013) kemudian terus turun menjadi 52,27\% (pada 2015). Sedangkan untuk merek GSM Tri dan XL juga memperlihatkan perubahan persentase konsumen setiap tahun yang relatif sangat sedikit penurunan awalnya pada 2012 sebesar 9,19\% dan 3,44\%, masing-masing Tri dan XL, selanjutnya turun $8,23 \%$ dan $3,17 \%$ tahun 2013 , lalu menjadi $7,90 \%$ dan $2,86 \%$ di tahun 2015 . Kemudian untuk pengguna Simpati, awalnya hanya 22,98\% pada 2012, namun tahun-tahun berikut menunjukkan peningkatan. Dan hanya IM3 yang awal relatif sedikit meningkat, yaitu 8,04\% pada 2012 lalu menjadi 9,23\% (2013) yang selanjutnya dalam jangka panjang mengarah pada angka 8,21\% (periode steady).

Mahasiswa Fakultas Pertanian UNSRAT pengguna GSM untuk merek AS dan Simpati yang pada awal mendominasi persentase pengguna dan bahkan pada tahun-tahun berikutnya cenderung tetap mendominasi jumlah pengguna GSM. Pada tingkat kedua merek GSM IM3 dan Tri yang mendominasi pengguna GSM, dimana keduanya masing-masing mencapai nilai antara 5-10\% dari total pengguna.Dan selanjutnya, merek GSM XL, hanya mampu mencapai angka di bawah 5\% saja.Sedangkan merek GSM Axis dan Mentari belum mampu untuk masuk pada pasar dalam populasi mahasiswa Fakultas Pertanian UNSRAT Manado.

\section{Daftar Pustaka}

Aeker, D. A. 1997. Manajemen Ekuitas Merek, Memanfaatkan Nilai Dari Suatu Merek. Mitra Utama. Jakarta.

Bhat, Narayan. 2008. An Introduction to Queueing Theory. Birkhäuser, Boston.

Djan, I. dan Ruvendi, R. 2006.Prediksi Perpindahan Penggunaan Merek Handphone di Kalangan Mahasiswa (Studi Kasus Pada Mahasiswa STIE Binaniaga).Jurnal Ilmiah Binaniaga.Vol 2 No.1.

Hasdianti, R. 2006. MA-4173 Kapita Selekta Matematika Terapan I (Teori Antrian). Penerbit ITB. Bandung.

Hillier, F. S. and G. J, Lieberman. 2008. Introduction to Operation Research Eigth Edition Jilid 2. Penerbit Andi. Jogjakarta.

Howard, A. and Rorres, C. 2004. Aljabar Linier Elementer versi Aplikasi.Edisi ke-8, jilid 2.Terjemahan Izham Harmein dan Julian Gresdando.Erlangga. Jakarta.

Kotler, P. dan K. L. Keller. 2007. Manajemen Pemasaran. Terjemahan PT INDEKS Kelompok Media. Jakarta.

Mahe, 2007. Pengaruh Penempatan (positioning) Produk terhadap Citra Produk(Studi pada Pengguna kartu HP Simpati di Kota Blitar). [on- 
line]

http://one.indoskripsi.com/judul-

skripsi/manajemen/pengaruh-penempatan-

positioning-produk terhadap-citra-produk-studipada-peng

Mulyono, S. 2007. Riset Operasi.Fakultas Ekonomi Universitas Indonesia. Jakarta.

Sitindaon, W. B. 2010. Analisa Perpindahan Merek Handphone Dengan Rantai Markov [Skipsi].FAKULTAS PERTANIAN USU. Medan.
Walpole, R. E. 1992. Pengantar Statistika. Edisi ke-3. Terjemahan Bambang Sumantri. Gramedia. Jakarta.

Yakub, R. 2008. Dinamika Rantai Markov Dengan Dua Komponen[Skripsi]. FAKULTAS PERTANIAN USU. Medan. 